\title{
A Case of Lean Idiopathic Hirsutism not Having Insulin Resistant Unresponsive to Conventional Treatment for Hirsutism-A Case Report
}

\author{
Kulvinder Kaur ${ }^{1 *}$, Gautam Allahbadia ${ }^{2}$ and Mandeep Singh ${ }^{3}$ \\ ${ }^{1}$ Scientific Director, DR Kulvinder Kaur Centre for Human Reproduction, India \\ ${ }^{2}$ Scientific Director, Rotunda-A Centre for Human reproduction, India \\ ${ }^{3}$ Consultant Neurologist, Swami Satyanand Hospital, India
}

Submission: April 16, 2018; Published: June 08, 2018

*Corresponding author: Kulvinder Kochar Kaur, Scientific Director, DR Kulvinder Kaur Centre for Human Reproduction, 721, G.T.B. Nagar, Punjab, India, Tel: 91-181-9501358180; Email: kulvinder.dr@gmail.com

\begin{abstract}
Hirsutism is the presence of terminal (coarse) hairs in females in a male like pattern, which affects $5-10 \%$ of women of the sex steroids androgens are the most important in determining the type and distribution of hairs over the human body. Under the influence of androgens hair follicles that are producing vellus type hairs can be stimulated to begin producing terminal hairs. The activity of local 5 alpha reductase $(5$ alpha RA) determines to a great extent the production of dihydrotestosterone (DHT) and consequently the effects of androgens on hair follicles. The commonest cause is an ovulation, secondary to PCOS, a fairly common disorder, affecting 6-10\% of women of reproductive age group. Besides PCOS other hormonal causes like thyroid hormone deficiency, growth hormone deficiency or hyperprolacinaemia, or hyperinsulinemia or IR may act on their own or synergistically increasing adrenal androgens. A serum $\mathrm{T}$ (Testosterone) over $2 \mathrm{ng} / \mathrm{ml}$ warrants exploring for an androgen secreting tumor. Other causes include non classical adrenal hyperplasia. Occasionally it may not be because of any these causes when it is termed idiopathic hirsutism (IH). Normally these patients of IH respond to 5 alpha reductase inhibitors. Recently high incidence of association of IR has been reported in lean IH. We report a case of lean IH not having IR and very unresponsive to treatment although we are trying to follow her up before undertaking any type of eflornithine cream or laser therapy.
\end{abstract}

Keywords: Hirsutism; Insulin resistant; Dihydrotestosterone; Androgens hair follicles; Ovulation; Hyperprolacinaemia; Hyperinsulinemia; Idiopathic hirsutism; Lean; 5 alpha reductase inhibitors; Poly cystic ovary syndrome; Adrenal hyperplasia; Haemogram; Ultrasonography; Drosperinone; Metformin; Flutamide; Testostosterone; Eumenorrheic; Isoenzymes; Spironolactone

Abbreviations: NCAH: Non Classical Adrenal Hyperplasia; PCOS: Poly Cystic Ovary Syndrome; IH: Idiopathic Hirsutism; IR: Insulin Resistance; DHT: Dihydrotestosterone; RA: Alpha Reductase

\section{Introduction}

Hirsutism is defined as the terminal hair on the body of a female patient, which is distributed in a male like pattern. It roughly affects $5-10 \%$ of women [1-4]. In most women hirsutism indicates the presence of one of the conditions like Poly cystic ovary syndrome (PCOS), androgen producing tumors, non classical adrenal hyperplasia ( $\mathrm{NCAH})$ or syndrome of severe insulin resistance, than being an isolated disorder with $60-70 \%$ cases accounted for by PCOS. Occasionally it may not be because of any of these causes when it is termed as idiopathic Hirsutism (IH) or peripheral Hirsutism [5]. Although often it is referred to as familial hirsutism, but this should not be used for IH as it has been shown that other causes of hyperandrogenemia like PCOS and NCAH show a strong familial distribution [4]. It needs treatment as it affects quality of life [6]. Here we report a case of unmarried girl having very low BMI, with IH, not having insulin resistance (IR), resistant to commonly used medications.

\section{Case Report}

A 28year old unmarried girl presented with history of hirsutism on face, abdomen, thighs for the last 5yrs for which she had received Metformin tid, spironolactone $100 \mathrm{mg}$ od for the past $5 \mathrm{mths}$ continuously without showing much improvement without any GTT./insulin, and normal serum testosterone, Her cycles were 1-2/30days regular though scanty. On examination her height was $44 \mathrm{~kg}$. Weight $44 \mathrm{~kg}$ giving a BMI of $17.40 \mathrm{~kg} / \mathrm{m} 2$, BP was $90 / 60 \mathrm{mmHg}$. Distribution of hair was as follows mild increase in hair on upper lips, chin, side burns, eye brows, very 
thick coarse terminal hair on upper and lower abdomen as well as on upper and lower back, around areola on both breasts, very thick coarse terminal pubic hair giving a modified ferriman gallway score of 9 [7]. External genitalia were normal, no signs of virilization were seen including no clitoromegaly and no hypertrophy of labial folds, normal hymen. Investigations were as follows S FSH-8.72Miu/ml(3-10), S LH-6.79Miu/ml(3-12), s Prolactin-7.984ng/ml(3-25ng/ml), Thyroid function tests were within normal limits, S.Testosterone (total)-38.38ng/dl(14-76), free testosterone-<72pg/ml(below normal range) following 5 mths of spironolactone omitted for 3 Days

\section{GTT-Fasting -90mg}

1 hour after 75 gm glucose -193mg, 2hr-156mg

S.I nsulin $2 \mathrm{hr}$ post glucose- $45 \mathrm{miu} / \mathrm{ml}$

S.DHES-236.3 $\mu \mathrm{g} / \mathrm{dl}(35-430)$

S.cortisol-within normal limits

$17 \alpha$ hydroxyl $(\mathrm{OH})$ progesterone (17alpha OH Pg )-1.41ng/ $\mathrm{ml}(0.1-0.8$-follicular phase

\section{6-2.3-luteal phase}

\section{3-1.4-ovulation}

\section{$<3.2$-post ACTH}

Since it was $<200 \mathrm{ng} / \mathrm{dl}$ ruling out NCAH, ACTH stimulation was not done

Haemogram was WNL-Hb-12gm, TLC-13, 100, DLC-P75, L20, M2E3, ESR-52-decreased to 30 after an antibiotic course, Hiv, hcv, hBsAg-Non reactive BT-1'45"/CT-slightly prolonged -8' hence PT, PTTK were done-PT-14.7sec (10-14sec) PTTK-46" (35-45")-borderline prolonged. Hence LFT was done which was within normal limits.

Ultrasonography transabdominal revealed a normal sized uterus with ovaries showing decreased AFC with a follicular cyst in right ovary Metformin, spironolactone were omitted and she has been put on a drosperinone containing OC along with flutamide $75 \mathrm{mg}$ daily besides improving her diet to improve BMI. In her case an ovulation could not be checked since she was already on antiandrogens and wanted treatment on day 2 presentation and having psychological effects of long standing hirsutism. She gained $1 \mathrm{~kg}$ in one month, still there is increased growth of resistant terminal hair and response is being monitored with cyclic yasmin and low dose flutamide for a minimum of $6 \mathrm{mths}$-1year based on response before shifting to eflornithine cream and any laser therapy with licorice.

\section{Conclusion}

This is a case of possibly IH although spontaneous an ovulation could not be checked as patient presented late with many medications without investigations to rule out hyper insulinemia, received full dose spironolactone with total testosterone falling within normal range, and on start free testostosterone suppressed below reference range. Although the definition of IH has been an evolving process, the diagnosis of IH should only be applied in hirsute patients with normal ovulatory function and circulating androgen levels. A history of regular menses in not sufficient to exclude ovulatory dysfunction, since up to $40 \%$ of eumenorrheic hirsute women are an ovulatory. The diagnosis of $\mathrm{IH}$ when strictly defined will include $<20 \%$ of all hirsute women. The pathophysiology of IH is presumed to be a primary increase in skin 5 alpha-reductase ( 5 alpha RA), possibly both isoenzymes, namely type 1 and type 2 activity. The activity of local 5 alpha RA determines to a great extent the function of Dihydrotestosterone (DHT), and consequently the effect of androgens on hair follicles [5]. Also there is a higher frequency of insulin resistance (IR) in lean hirsute women regardless of them having PCOS or IH $[8,9]$. In our patient who was lean, there was no evidence of IR. Therapeutically they respond to antiandrogens or 5 alpha RA inhibitor therapy Pharmacological suppression of ovarian or adrenal androgen secretion may be of additional, although limited benefit. Idea of using yasmin(combined OC having ethinyl estradiol with drosperinone) is that there is a rise in SHBG with combined OC's due to the estrogen component, which cause decrease in circulating free testosterone. This raised SHBG increases binding capacity of androgens, which is associated with decreased free testosterone. Since production of androgens is a LH dependent process these combined OC's suppress LH. Combined OC's having drosperinone, a derivative of spironolactone has been found to be more effective, in contrast to OC's with 2 nd generation progestins. A minimum of $6 \mathrm{mths}$ -1yr therapy with these OC's is required to achieve meaningful therapeutic benefit. Spironolactone also has 5alpha RA but it also has slow action and was received for $5 \mathrm{mths}$. Other drugs like finasteride and flutamide share this activity and flutamide is being used in lower doses with the fear of hepatotoxicity since finasteride is not as effective as in prostate cancer [4]. New therapeutic strategies like laser epilation, or use of new biological response modifiers may play a role in offering a more effective means of removing uncontrolled hair. Eflornithine cream can be applied on face after laser, bleaching once long term OC's have been reduced. Faghi et al. [10] compared the efficacy of alexandrite laser vs alexandrite laser plus topical licorice and found this combination to be more effective in patients of IH. We are waiting for a response of slowing the growth of the terminal hair before any laser or eflornithine cream is applied. In view of her borderline coagulation profile we are using flutamide in low doses rather than full $250 \mathrm{mg}$ dose for fear of hepatotoxicity.

\section{References}

1. Escobar Morreale HF, Carmina E, Dewailly D, Gambineri A, Kelestimur F, et al. (2012) Epidemiology, diagnosis and management of hirsutism: a consensus statement by the androgen excess and polycystic ovary syndrome society. Hum Reprod Update 18(2): 146-170.

2. Heimalatha AL, Konananahali P (2005) Bilateral malignant Brenner tumor of ovary. J Obstet Gynecol India 55(1): 81-82. 
3. Katke RD, Kiran LC, Saraogi M, Sarode S, Thawal R(2014)Giant borderline mucinous cystadenoma with previous 3 caesarians. J Post graduate Gynaecol Obstet 1: 1-4.

4. Kochar Kaur Kulvinder, Allahbadia GN, Singh M (2017) Hirsutsm A comprehensive of embryology, Aetiopathogenesis and Therapeutic Approach. J Gynecol Womens Health 2(2): 001-0012.

5. Azziz R, Carmina E, Sawaya ME (2000) Idiopathic Hirsutism. Endocrine Reviews 21(4): 347-62.

6. Sonino N, Faval F, Mani E, Belluardo P, Boscaro M (1993) Quality of life of the hirsute women. Postgrad Med J 69(809): 186-189.

7. Ferriman D, Gallwey JD (1961) Clinical assessment of body hair growth in women. J Clin Endocrinol Metab 21: 1440-1442.
8. Arduc A, Sarıcam O, Dogan BA, Tuna MM, Tutuncu YA, et al. (2015) Should insulin resistance be screenedin lean hirsute women? Gynecol Endocrinol 31(4): 291-295.

9. Ucak S, Basat O, Satir E, Aluntas Y (2012) Evaluation of varius insulin sensitivity indices in lean idiopthis hirsutism patients. Endocr J 59(4): 291-296.

10. Faghihi G, Iraji F, Abtai Naeini B, Saffar B, Saffael A, Pourazizi M, Aslani A, Nilforoshzadeh MA (2015) Complementary therapies for idiopthis hirsutism: Topical licorice as promising option. Evidence based Complemetary and Alternative Medicine Pp 6.

\section{Your next submission with Juniper Publishers will reach you the below assets}

- Quality Editorial service

- Swift Peer Review

- Reprints availability

- E-prints Service

- Manuscript Podcast for convenient understanding

- Global attainment for your research

- Manuscript accessibility in different formats

( Pdf, E-pub, Full Text, Audio)

- Unceasing customer service

Track the below URL for one-step submission https://juniperpublishers.com/online-submission.php 